\title{
QUANTIFYING THE DENSITY-QUALITY OF PHOTOGRAMMETRICALLY CREATED POINT-CLOUDS OF LINEAR ARCHITECTURAL/URBAN ELEMENTS AS A FUNCTION OF SHOOTING DISTANCES AND NUMBER OF CAMERA POSITIONS I.E. SHOOTING-DIRECTIONS
}

UDC 528.7

\section{Djordje Djordjevic, Gordana Djukanovic, Dusan Filipovic}

University of Belgrade, Faculty of Architecture, Belgrade, Serbia

\begin{abstract}
This paper examines the impact of various object-to-camera distances and the number of station-points i.e. various shooting directions with regard to the obtained Density-quality of photogrammetrically created Point-clouds - as digital representations of the existent linear architectural/urban objects/elements.

According to an artificial (purified) experimental scene used, the conclusion is that with the chosen focal lengths/object-to-camera distances, with shooting directions perpendicular to the axis of that object, with station-points uniformly radially distributed around it (at a circle of 360deg), and with the obtained values of photogrammetric-software process-quality outputs which belong to the recommended ranges, the achieved density-level of the created Point-clouds may be treated as independent on the camera's radial-movement angle but dependent on the percentage of "Object's Photo-Coverage”: the lower the Coverage, the lower the density. Also, regardless of the Coverage level, the majority of the generated points are generally more "densimetrically" precise than they are "densimetrically" accurate.
\end{abstract}

Key words: Architectural Photogrammetry,Image-Based 3D-Modeling, Point-Cloud, Density, Precision, Accuracy.

\section{INTRODUCTION AND BACKGROUND}

The previous work in the subject-related field was directed at research criteria relevant for the quantifying: (a) the metric quality characteristics of photogrammetrically generated Pointclouds of linear objects - obtained in the function of shooting distances and a number of

Received November 1, 2015 / Accepted November 20, 2015

Corresponding author: Djordje Djordjevic

University of Belgrade, Faculty of Architecture, 11000 Belgrade, Bulevar Kralja Aleksandra 73/II, Serbia

E-mail: djordje@arh.bg.ac.rs 
camera positions i.e. shooting-directions perpendicular to the axes of targeted objects [2], and (b) both the metric and the density-quality characteristics of photogrammetrically generated Point-clouds, obtained for horizontal shooting directions - as a function of the linear objects' inclination angle (measured from a horizontal plane) [3]. Other studies tackling this area have mostly been targeting the investigation criteria required to quantify the obtained metric quality of the created Point-clouds of planar and volumetric entities only [1], [5], [7].

Bearing in mind that a high-quality photogrammetric Point-cloud creation of the linear objects/elements (including architectural/urban ones) is more complicated and sophisticated than that of the planar and volumetric entities (like terrains, walls and other, especially, amorphous architectural surface-structures), a further research into this topic is inevitable. So, the already revealed conclusions of the previous work, as well as this one, are important to broaden not only the knowledge related to architectural photogrammetry, but to give a useful contribution to all aspects of architectural digitization practice (regarding the necessary preshooting procedures, shooting procedures and photogrammetric software processing).

In the light of the foregoing, this paper should scientifically quantify the obtained densityquality of photogrammetrically created linear object's Point-clouds as a function of shooting distances and a number of camera positions i.e. shooting directions (perpendicular to the axis of that object) - respecting a pre-determined quality-valorisation criterion. The conclusions (arising from a comparative analysis of the obtained/cross-referenced results) shall make it possible to avoid potential mistakes, often unintentionally made: both in preparation and realization stages. Thus, it is becoming possible to minimize any eventual decrease of the density-quality of Point-clouds as photogrammetric representations of the existent linear architectural/urban objects/elements.

This investigation is a continuation of the initial research performed by Djordjevic et al. [2]. Because the input data-sets are the same for both experiments (such as: determinants, test-field setup, equipment and technology used, as well as the adjustment of the shooting and processing parameters), the ,raw " outputs which are specific to the current investigation were obtained simultaneously with those specific to that initial ("referral") research. Thus, it is possible here to take over (from that "referral" experiment) all fundamental data in common and the mentioned "raw" outputs. But, in order to preserve consistency and clarity of the actual methodological approach, except for what can be "inherited", all additional information that are qualified as important for a better understanding of the actual work, will also be repeated here, but in brief.

Based on the those ("inherited") "raw" data, all calculations relevant from the density point of view (including their cross-referencing and analysis) will be performed here.

\section{TEST-FIELD SETUP}

Bearing in mind previously mentioned, the Test-Field used was an artificial experimental scene defined in an empty indoor space. Because that "purified" space was out of reach of natural targets (that is not the case in real scenes), "Ringed Automatically Detected" targets ("RAD" targets) were added so that the computer-guided photo-matching (and pointreferencing) procedures could be performed with satisfactory precision and accuracy [2] (Fig. 1). 

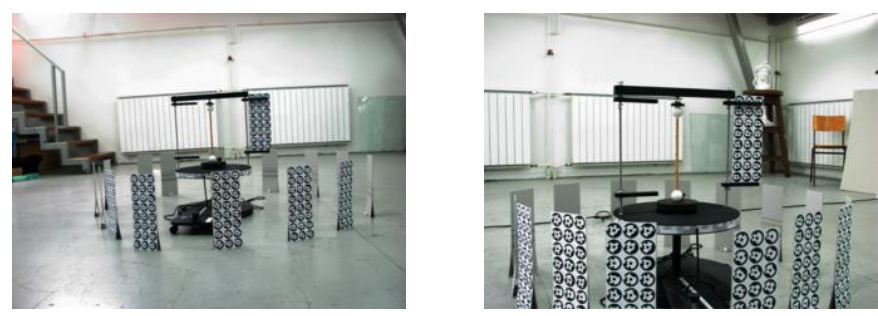

Fig. 1 Artificial experimental scene (Referral Test-Field): centrally positioned equipment used to fix vertically the experimental linear object; "RAD" target panels distributed radially in its surrounding

Referral Test-Field included the following elements [2]:

1. An experimental linear object ("Stick") with two white spherical targets fixed at both ends of the stick making the axis easily identifiable by the photogrammetric software used (Fig.2(a)).

2. An artificial light source (professional photographic reflector), used to generate an additional amount of light and to annul the existent impact of light-sources on shadow appearance and any imbalanced saturation distribution on the stick's surface.

3. A camera, that rotated around the stick, so that the stick's axis represented the axis of rotation (the camera rotation plane was perpendicular to the stick). The station-points were placed at three various circle paths (with radiuses of $70 \mathrm{~cm}, 110 \mathrm{~cm}$ and $220 \mathrm{~cm}$ ). The number of uniformly distributed station-points ranged from 24 (determined by a $15 \mathrm{deg}$ camera's radial-movement angle), 12 (determined by a 30deg radial movement) to 8 (determined by a $45 \mathrm{deg}$ radial movement). The target-point for all photos was the mid-point of the stick's axis and the shooting directions were always perpendicular to that axis. Following the foregoing, 9 experimental cases were carried out. They were designated as "70/15", "70/30", "70/45", "110/15", "110/30", "110/45", "220/15", "220/30" and "220/45" and will be identically named in this research.

4. Vertical "RAD" target panels ( $\mathrm{W}=15 \mathrm{~cm}, \mathrm{H}=35 \mathrm{~cm})$, placed on a horizontal floor and uniformly/radially stationed around the stick at a distance of $100 \mathrm{~cm}(15 \mathrm{pcs} / 24 \mathrm{deg})$. Each panel included 24 printed "RAD" targets (created by the photogrammetric software used), each with a unique graphic code. (Fig. 2(b))

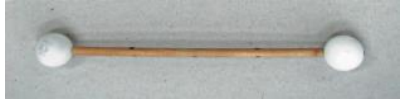

(a)

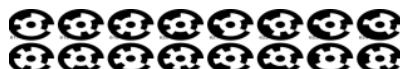

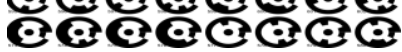

(b)

Fig. 2 (a) Experimental linear object: cylindrical wooden stick ( $1=25 \mathrm{~cm}$, diameter $=10 \mathrm{~mm})$

(b) Printed "RAD" target panel ( $\mathrm{w}=15 \mathrm{~cm}, \mathrm{~h}=35 \mathrm{~cm})$ (Source: Djordjevic et al. [2]) 


\section{EQUIPMENT AND TECHNOLOGY USED}

The following equipment was used [2]:

- Computer: Acer Aspire Timeline X with IntelCore i5 - 45DM processor and 8GB DDR3 RAM,

- Professional photogrammetric software, produced by EosSystems Inc: PhotomodelerScanner ("PMS"), Version: 2014.0.2.1338 (64-bit),

- Mesh-analysis and comparison software, produced by D. Girardeau-Montaut: CloudCompare ("C2C"), Version 2.5.3 (64bit), and

- Semi-professional 8MP camera: PowerShot S5 IS, produced by Canon Corp.

\section{Shooting And Processing PARAMETERs/SETtings DeFinition}

The following shooting and processing parameters were set [2]:

- Regarding the shooting options: (a) short (wide-angle) lens "f" of $6.0 \mathrm{~mm}$, (b) Aperture-priority Mode with f-stop of $1 / 15$, (c) Shutter-Speed of $1 / 15 \mathrm{sec}$, and (d) ISO-speed of 400. The following camera settings were turned off: (a) Auto-focus, (b) Digital zoom, (c) Image stabilization, (d) Auto-sharpening and (f) Image- rotation. The Image-size of all photos was the same (maximum possible for the chosen camera model) - set to $3264 / 2448$ pxls, while the Image-quality is set to "Superfine".

- Regarding the Point-cloud creation: Eos-Systems' innovative "Multi-view Stereo Technique" ("MVS") was used, with chosen input-parameters (Table 1).

Table 1 Chosen MVS input-parameters of PMS-software (Source: Djordjevic et al. [2])

\begin{tabular}{ll}
\hline MVS-Parameters & Setup/Ref. Value \\
\hline Min. Visible Images & $3(\max .10)$ \\
Min. Angle of Point & $10(>0)$ \\
Texture Strength & $0.1(\max 1)$ \\
Down-sample Level & $1(>0)$ \\
Point Spacing & $2(>0)$ \\
\hline
\end{tabular}

\begin{tabular}{ll}
\hline MVS-Parameters & Setup/Ref. Value \\
\hline Max. Group Size & $20(>0)$ \\
Window Radius & $3(>0)$ \\
Number of iter. & $1(\max .10)$ \\
Curvature Factor & $0.5(\min .0)$ \\
\hline
\end{tabular}

\section{MeTHODOLOGY}

Due to the geometric nature of the experimental cylinder (primitive is Surface of Revolution), not classical Stereo-photo-strips (obtained by camera translation), but radial ones (with minimum shooting-angle separation of $15 \mathrm{deg}$ ) were the basis of the MVS procedure performed in the referral experiment [2]. The final results were in the form of nine different Point-clouds (Fig. 3), used again here - but for analysis of the achieved density. Because the MSV creation process was subsequent to a 3D-reconstruction process [2], the outcomes of 3D-reconstruction might also have a dominant influence on the achieved (currently investigated) Density-quality of the "inherited" Point-clouds [3], [4].

The Density-quality research of those Point-clouds will be dealt with on the same two levels as in the subject-related experiment [3]: (a) with regard to the characteristics of the directly "inherited" Process-quality descriptors [2] and (b) by an analysis of the Densityquality descriptors - newly calculated here (as specific for the actual research). 
Because of the nature, four already defined terms [3] can also be used in further analysis:

(1) Average distance/closeness,

(2) Densimetric error,

(3) Densimetric accuracy, and

(4) Densimetric precision.

For the same reason, the identical set of Density-quality descriptors will be analysed here:

(1) The Total number of all generated Cloud-points,

(2) The Abundance percentage of specific Cloud-points (consistent with the Total number of those created): the "densimetrically" accurate points, both the "densimetrically" precise+accurate points, the "densimetrically" precise but inaccurate points and both the "densimetrically" imprecise+inaccurate points,

(3) The difference between the previously found Abundance percentage of specific points and their statistically acceptable percentage,

(4) The closeness (i.e. distance/densimetric error) between the created "neighbouring" Cloud-points: (a) the densimetrically both accurate+precise points and (b) the densimetrically precise but inaccurate points,

(5) The average Point-cloud density - calculated using: (i) all generated Cloud-points and (ii) both "densimetrically" accurate+precise points.

\section{EXPERIMENTAL RESULTS}

Fig. 3 shows nine Point-clouds (created in the referral experiment [2]), with the corresponding density distribution.

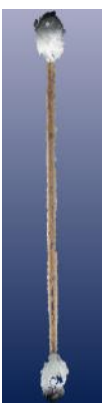

$70 / 15$

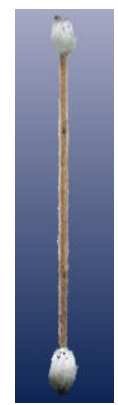

$70 / 30$

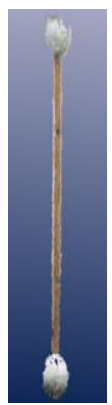

$70 / 45$

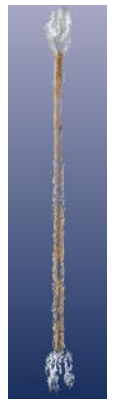

$110 / 15$

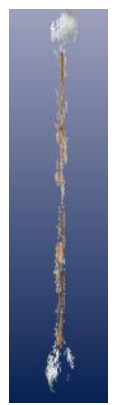

$110 / 30$

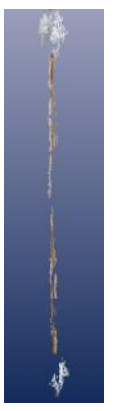

$110 / 45$

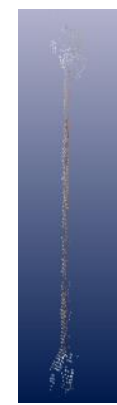

$220 / 15$

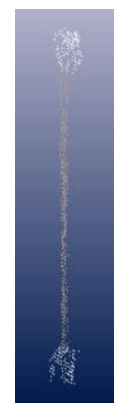

$220 / 30 \quad 220 / 45$

Fig. 3 Results of the MVS-process: Generated Point-clouds relevant to each experimental case, with the corresponding density distribution (Source: Djordjevic et al. [2])

\subsection{Process-quality outputs}

Because there were no Process Status Reports (generated by PMS software in the referral experiment [2]) with problem notifications and possible suggestions, all nine experimental cases were treated as successfully processed. So, there were no negative influences of 3Dreconstruction process outcomes on the achieved Point-clouds Metric-quality and, thus, there will neither be negative consequences on their Density-quality. Only the unusual/ 
unexpected values of the Process-quality descriptors which are assumed as Densityquality dependent, will be dealt with here at a later stage - by analysing their possible impact on the achieved Density-quality.

\subsection{MVS process outputs}

As in the subject-related experiment [3] (concerning the Density-quality), the average point-to-all-its neighbours closeness (i.e. distance/densimetric error) is automatically analysed (regarding all created points of each separate experimental Cloud) and calculated by $\mathrm{C} 2 \mathrm{C}$-software (in the same way) - by the usage of identical pre-sets ("Searching radius" is set to 1 , the densimetric accuracy is calculated according to a given scale of 1 ; to increase the densimetric precision (by decreasing the distance threshold used in calculation), "Octreelevel" is set to 8).

The $\mathrm{C} 2 \mathrm{C}$ output data are in the form of newly created Density-quality Histograms (Fig.4). All Histograms are gradually colored (from red/on the right to blue/on the left) representing mutual Point-To-All-Its-Neighbours closeness (i.e. distance/densimetric error) variations (the red highlights the strongest, while the dark blue - close to Origin, shows the smallest level of those variations). Note that the larger the closeness between neighbouring Cloud-points, the smaller the distance/densimetric error [3]. The thin white curve (as a part of each Histogram) represents the calculated statistical law of the mentioned "closeness/distance distribution". As in the subject-related experiment [3], this law is based on the obtained Gaussian Normal Distribution characteristics (i.e. the calculated values of Mean and Gaussian Standard Deviation (Sigma), visible at the upper part (text field) of each Histogram). The vertical reddish bar marks the approximate position of each concrete Pointclouds' Mean i.e. its average closeness (i.e. distance/densimetric error) distribution value.

According to the subject-related experiment [3], each generated Cloud-point can be declared as "densimetrically precise" (i.e. with a statistically acceptable precision) if its densimetric error value is positioned symmetrically with regard to the vertical tendency ("Mean") line and belongs to the " Gaussian Chart field" (i.e. under the Gaussian Normal Distribution Curve) whose maximal width is 6xSigma-standard deviation (i.e. (+-) 3xSigma from the Mean). On the other hand, the densimetric error values, which declare the corresponding Cloud-points as "densimetrically accurate" (i.e. with a statistically acceptable accuracy), belong to the "Chart field" parts positioned from the Mean line towards the Chart's Y-axis (i.e. Reference line). If the obtained densimetric error distribution ("spread") strictly fits the Gaussian Normal Distribution characteristics (showing a total "covering" with Gaussian Curve), there will be exactly $50 \%$ of densimetrically both precise+accurate points and $50 \%$ of densimetrically precise but inaccurate points. It is obvious that every divergence from the Gaussian Normal Distribution, by increasing the number/percentage of either densimetrically both precise+accurate points (in favour of others) or densimetrically precise but inaccurate points (in favour of densimetrically both imprecise+inaccurate ones) is to be considered as a density-quality asset. 


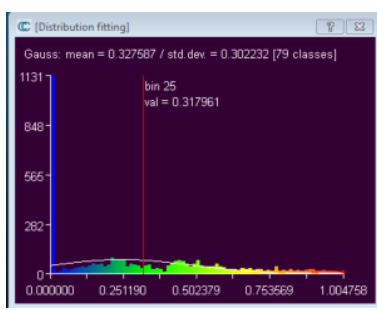

$70 / 15$

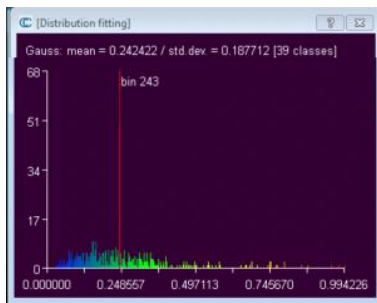

$110 / 15$

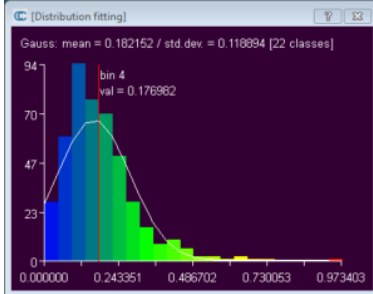

$220 / 15$

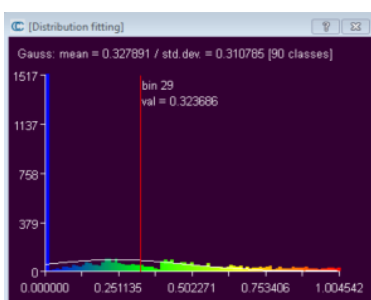

$70 / 30$

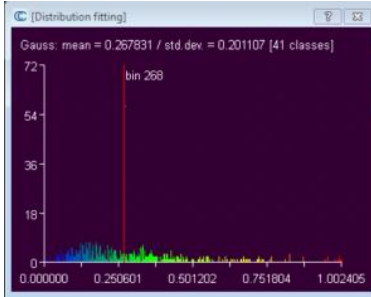

$110 / 30$

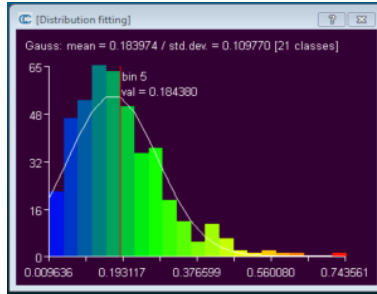

$220 / 30$

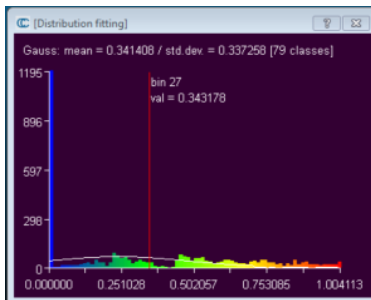

$70 / 45$

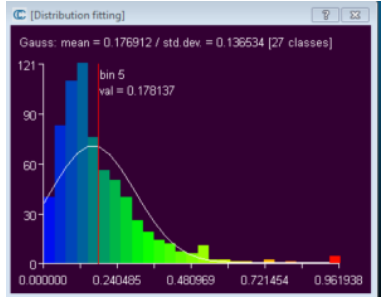

$110 / 45$

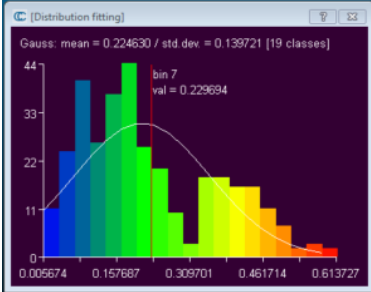

$220 / 45$

Fig. 4 The obtained Density-quality Histograms and the corresponding Gaussian Normal Distribution Curves, related to each experimental case (Point-To-All-Its-Neighbours closeness (i.e. distance/densimetric error) values: Gradient norms, Local density: $r=1$ )

Following the data collected from these histograms (with regard to the corresponding Mean and Sigma), it is possible to calculate the values of the analysed density-quality descriptors (related to densimetrically both precise+accurate, densimetrically precise but inaccurate and densimetrically imprecise+inaccurate points), in a form of percentages of all created points that a specific Cloud consists of. These descriptors' values are graphically represented in the form of Density-quality Charts (shown below), created by Excel software. To generalize the results, each chart represents not only the actual values of the obtained Density-quality descriptors (,dot”-marked), but also the corresponding logarithmic Trendlines ("marked as wide continuous lines). 


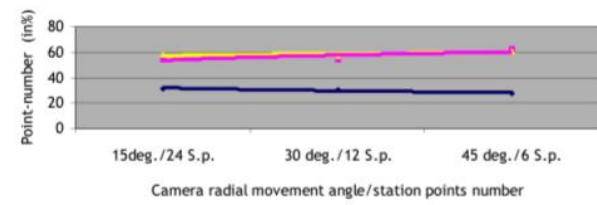

- Dist70

- Dist110

Distz20

Log. (Dist220)

Camera radial movement angle/station points number

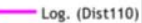

(a)

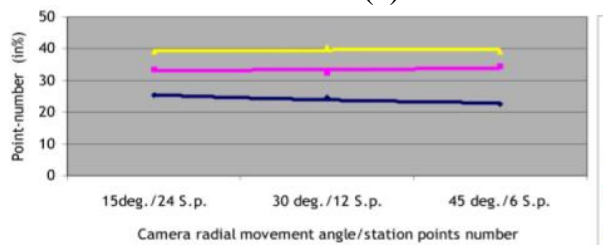

- Dist70

- Dist110 Dist220

Log. (Dist220)

Camera radial movement angle/station points number

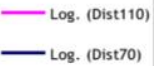

(b)

Chart 1 The Abundance percentage of specific Cloud-points (with regard to all created points) - as a function of the camera's radial-movement angle/station-points number i.e. shooting directions (values refer to: (a) densimetrically both precise+accurate points and (b) densimetrically precise but inaccurate points).
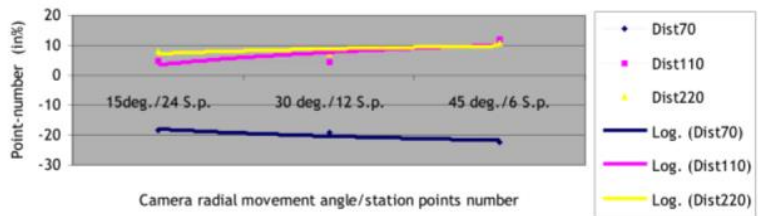

(a)

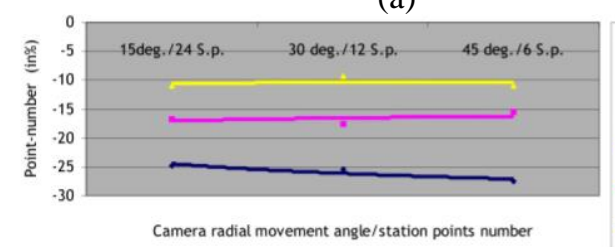

- Dist70

- Dist110 Dist220

Log. (Dist220)

Camera radial movement angle/station points number

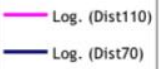

(b)

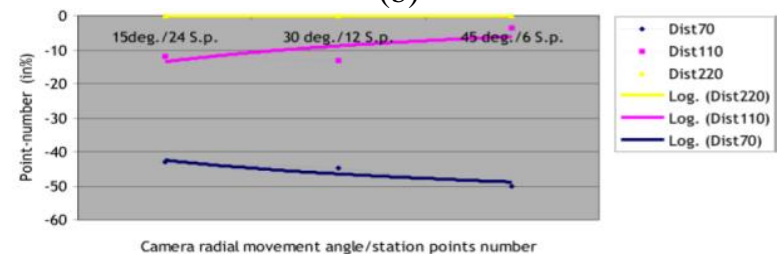

(c)

Chart 2 The difference between the previously found Abundance percentage of specific Cloud-points and their corresponding statistically acceptable percentage - as a function of the camera's radial-movement angle/station-points number i.e. shooting directions; the estimation is based on the calculated Gaussian Normal Distribution characteristics (values refer to: (a) densimetrically both precise+accurate points (ref. $=$ $\min .50 \%$ ), (b) densimetrically precise but inaccurate points (ref. $=\min .50 \%)$ and (c) densimetrically both imprecise+inaccurate points (ref. $=0 \%)$ ). 


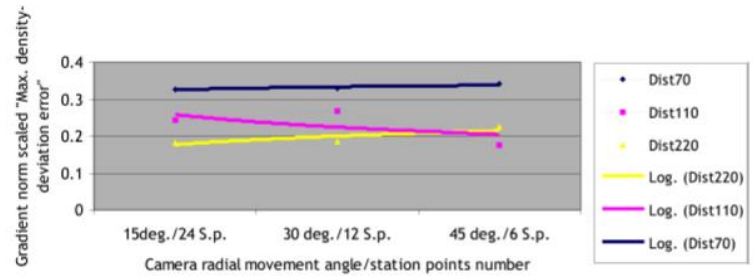

(a)

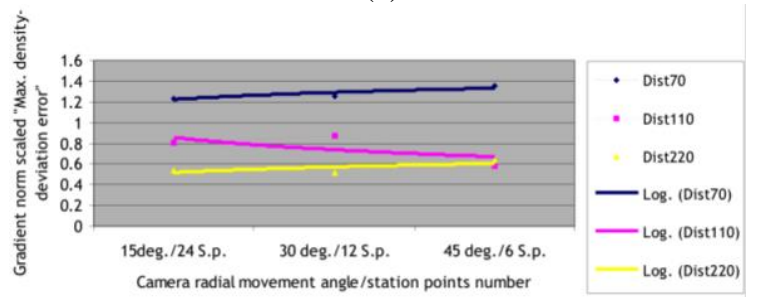

(b)

Chart 3 The closeness (i.e. distance/densimetric error) between the created "neighbouring" Cloud-points - as a function of the camera's radial-movement angle/station-points number i.e. shooting directions; the estimation is based on the calculated Gaussian Normal Distribution characteristics (values refer to: (a) densimetrically both precise+accurate points and (b) densimetrically precise but inaccurate points).

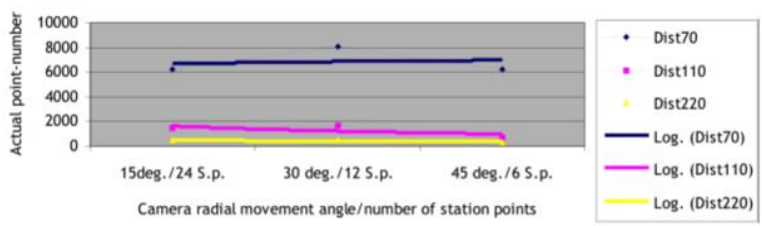

(a)

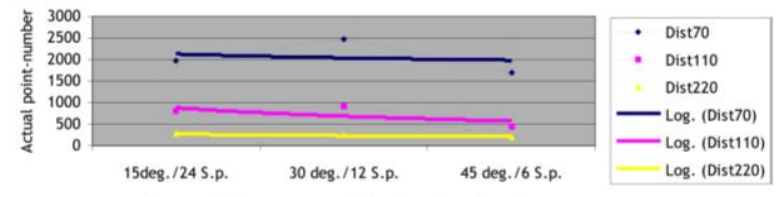

(b)

Chart 4 The Total number of generated Cloud-points - as a function of the camera's radial-movement angle/station-points number i.e. shooting directions, related to: (a) all generated points and (b) densimetrically both precise+accurate points. 


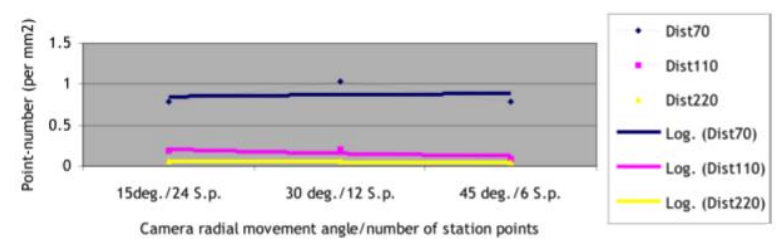

(a)

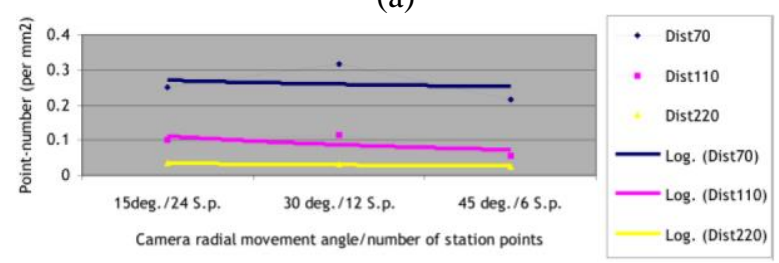

(b)

Charts 5 The average point-cloud density - as a function of the camera's radial-movement angle/station-points number i.e. shooting directions, related to: (a) all generated points and (b) densimetrically both precise+accurate points.

\section{DISCUSSION}

Seven Density-quality Histograms (of nine created) - related to the experimental cases $70 / 15,70 / 30,70 / 45,110 / 45,220 / 15,220 / 30$ and 220/45, clearly show visible Gaussian Normal Distribution Curves of the calculated densimetric error distribution. As regards these cases, the actual densimetric error distribution generally fits the statistically acceptable values, represented by the Gaussian Law. Contrary, the Gaussian Curves in the experimental cases 110/15 and $110 / 30$ are invisible, because of their significant shallowness as a result of generally too small values on the histogram's Reference-line (Y) axes (which describe the number/percentage of created Cloud-points having the same level of achieved densimetric error). Unfortunately, evidence for such (unexpected) features is inexistent now, because (at it was previously mentioned) the values of the process-quality descriptors (corresponding to these cases) were not atypical at all [2]. Given the aforesaid, it is not possible here to additionally discuss these histograms. Henceforth, such tendency will be investigated at a later stage.

In all experimental cases (presented Histograms), "emptiness" visible in "under-curve zones" on the corresponding Means' right sides (despite the fact that such emptiness is even situated "along" the distances" of $+3 *$ Sigma Standard deviation), cannot be treated as a Density-quality warning, but as an indicator of an obvious absence of densimetrically precise but inaccurate points. On the other hand, the "under-curve emptiness" also visible on the Means' left sides (cases 70/15, 70/30 and 70/45) shows some slight lack of densimetrically both precise+accurate points. Regardless of the same - „left“ Means' parts of the Histograms, a significant quantity of bluish-point "overcomes" (upper-curve-located) - highlights the dominant presence of densimetrically both precise+accurate points (whose Abundance drastically overcomes the statistically estimated values), declaring such trend as a positive.

All presented histograms i.e. the corresponding Gaussian Law Curves clearly show that there are no generated densimetrically accurate but imprecise Cloud-points at all. This is a result of the fact that the "left side" of each corresponding Gaussian Curve (whose "width" 
is: Mean - $3^{*}$ Sigma) is larger than its concrete Mean-To-Origin distance (all Gaussian Curves intersect the chart's "Reference-lines" above the Origin); the aforesaid is also present on histograms referring to the cases 110/15 and 110/30, but invisible there because of a too small picture format. Hence, the output data analysis will include densimetrically both precise+accurate points and densimetrically precise but inaccurate ones.

A deeper analysis of the obtained histograms will be based on the analysis of crossreferenced data taken from and presented on the related Density-quality charts.

Charts 1(a) and 1(b) show the following.

There are no differences between the Abundance percentages of densimetrically both precise+accurate points - shot from distances of $110 \mathrm{~cm}$ and $220 \mathrm{~cm}$ (there are approximately $60 \%$ of all generated points) (Chart 1(a)). The corresponding Trend-lines show that the Abundance slightly increases as the camera's radial-movement angle increases, which can be considered as insignificant. On the other hand, the Abundance percentage of the same type of created Cloud-points which relate to the case of dist70 is lower (approximately 30\% of all generated points) and shows also an insignificantly decreasing tendency. A smaller total number of the "natural" and "RAD" targets - visible/photographed from the distance of 70cm can be considered as the cause for the corresponding percentage decrease of densimetrically both precise+accurate points - shot from that distance ([1], [4]). Generally, it is possible to emphasize that the Abundance percentage of densimetrically both precise+accurate points is almost independent on the camera's radial-movement angle i.e. station-points number.

As concerns densimetrically precise but inaccurate points (Chart 1(b)), their Abundance percentages are balanced and almost not prone to the camera's radial-movement angle (i.e. station-points number) in the cases of shooting from distances of $110 \mathrm{~cm}$ and $220 \mathrm{~cm}$. The highest Abundance percentage refers to the cases of dist220 (approximately 40\%), dist110 (approximately 34\%), while the lowest refers to shots from dist70, showing a slight permanent decrease (from approximately $25 \%$ to approximately $22 \%$ ) as the camera's radial-movement angle increases. A smaller number of visible/photographed and processed both the "natural" and "RAD" targets in the case of dist110 and their smallest number in the case of dist70 can be the same (previously underlined) reason for the actual order of appearance of the corresponding Trend-lines.

In keeping with the nature of the content of Charts 2 , the featured negative values refer to the fact that the actual Abundance percentage of the specific analysed point-type is lower than its statistically acceptable percentage. This negative difference shall be treated as a "Deficit" of this type of points. On the other hand, the positive values of these differences correspond with the analysed points "Surplus" It is necessary to keep in mind that, given the specific nature (type) of these points, a deficit/surplus can point out to either a positive or a negative trend.

According to the above facts, Charts 2(a), 2(b) and 2(c) show the following.

In line with the experimental shooting distances, there exist obvious differences between the global behaviour of Trend-lines related to densimetrically both precise+accurate points (Chart 2(a)). The surplus-increase of the analysed points is characteristic to the cases related to dist 110 and dist220 (positive trend). As the camera's radial-movement angle increases, the surplus-increase is more evident in the case of dist 110 (it rises from approximately $5 \%$ to approximately $10 \%$ over the corresponding statistically acceptable value of a half of all generated points). The same type of points is less angle-dependent in the case of 220dist and shows a slight surplus-increase (from approximately $8 \%$ to approximately $10 \%$ ). With regard to both previously analysed shooting distances $(110 \mathrm{~cm}$ and $220 \mathrm{~cm})$, the point-surplus 
becomes equal for radial-movement angle of approximately $45 \mathrm{deg}$. On the other hand, as the radial-movement angle increases, dist70 is characterized by an insignificant deficit-increase which can be considered as almost constant (of approximately $20 \%$ in average) and, hence, the camera's radial-movement angle independent. An identical aforesaid reason may also be considered as the cause for such a tendency which relates to the case of dist70.

Concerning densimetrically precise but inaccurate points, all experimental distances are characterized by an obvious deficit of these points (Chart 2(b)). A minimal and constant (i.e. angle-independent) deficit of the mentioned points (of approximately 10\%) refers to dist220. A higher and almost constant (and, thus, angle-independent) deficit (of approximately $17 \%$ ) relates to dist 110 , while dist 70 is characterized by the highest deficit with a slight increasing tendency (from approximately $25 \%$ to approximately $27.5 \%$ ), which is prone to a camera's radial-movement angle increase. As previously said, a permanent decline of visible/photographed and processed both the "natural" and "RAD" targets numbers (from dist220 via dist110 to dist70), can be the reason for the current order of appearance of the corresponding Trend-lines ([1], [4]).

There is (as an extremely positive trend) a zero-deficit/surplus of the densimetrically both imprecise+inaccurate points in the case of dist 220 i.e. a zero-difference between the Abundance percentage of these points and their statistically acceptable Abundance percentage (of $0 \%$ of all generated points!)) (Chart 2(c)). On the other hand (due to the ref. value of $0 \%$ ), there is a surplus of the analysed type of points in the cases of dist70 and dist110 (as a negative qualifier in this context). The surplus that refers to the case of dist110 is lower than the one that refers to dist70, and shows a slight decrease (from approximately $13 \%$ to approximately $4 \%$ ) as the camera's radial-movement angle increases (which can be declared as a positive trend). On the contrary, the surplus referring to the case of dist70 is characterized by an "inverted" tendency (negative trend): there is a slight increase of difference (from approximately $43 \%$ to approximately $50 \%$ ) between the Abundance percentage of densimetrically both imprecise+inaccurate points and their referral i.e. the statistically acceptable Abundance percentage (of $0 \%$ of all generated points). The described tendencies can be explained by the same reason reiterated several times.

Charts 3(a) and 3(b) show the following.

The experimental cases related to dist70 and dist220 are characterized by the fact that the densimetric errors which refer to densimetrically both precise+accurate points increase as the camera's radial-movement angle increases - contrary to dist110 (Chart 3(a)). The mentioned (slight) increase - related to the case of dist70, can be considered as camera's radial-movement angle independent. On the other hand, the level of the densimetric errors that refer to the two other cases is prone to the camera's radial-movement angle change (the Trend-line of dist110 represents a decline of the densimetric error: from approximately 0.25 to approximately 0.2 , while the Trend-line of dist 220 shows a less abrupt densimetric error increase: from approximately 0.18 to approximately 0.21 ). Also, in the case of usage of 9 uniformly radially distributed station-points (at a circle of 360deg) i.e. for a constant shooting-angle separation (of approximately $37.5 \mathrm{deg}$ ), there is the same densimetric error (of approximately 0.2 ) which relates to the distances of $110 \mathrm{~cm}$ and $220 \mathrm{~cm}$.

The behaviour of the Trend-lines - related to densimetrically precise but inaccurate points (Chart 3(b) is similar to that of densimetrically both precise+accurate points (Chart 3(a)). Namely, dist70 and dist220 are characterized by the fact that the densimetric error slightly increases as the camera's radial-movement angle increases, representing 
insignificant angle-dependences. On the contrary, dist110 shows a densimetric error decreasing tendency as the camera's radial-movement angle increases (declination of dist110 Trend-line is in the range from approximately 0.85 to approximately 0.70 , while the Trend-line inclinations of both the dist220 and the dist70 are from approximately 0.55 to 0.60 and respectively from approximately 1.20 to 1.35 ). Also, in the case of usage of 6 uniformly radially distributed station-points (at a circle of $360 \mathrm{deg}$ ) i.e. for a constant shooting-angle separation of approximately 45deg, there is almost the same densimetric error (of approximately 0.60 ) which relates to shooting distances of $110 \mathrm{~cm}$ and $220 \mathrm{~cm}$.

The global densimetric error behaviour, related to the previously analysed shooting distances can be considered as a consequence of the behaviour of relevant process-quality descriptors, such as: "Point Marking Residual" (especially "Maximum" and "Overall" ones) and "Point/Surface Angle" (especially "Average" one). Namely, the Trend-lines of both foregoing process-quality descriptors clearly show why the process imprecision decreases as the shooting distance and the camera's radial-movement angle increases ([2], [3], [4]).

Charts 4 show the following.

The largest number of all generated Cloud-points refers to the case of dist70 (of approx. 6500), while a drastically smaller number refers to the cases of dist110 (of approx. 1250 in average) and dist220 (of approx. 300) (Chart 4(a)). The presented Trendlines show that the Total number of all generated Cloud-points is independent on the camera's radial-movement angle - in the cases of dist70 and dist220, while dist110 is characterized by slight angle-dependence which can be treated as insignificant.

Similarly, the Total number of densimetrically both precise+accurate points that refer to dist70 is significantly higher than in the cases of dist110 and dist220 (Chart 4(b)). Also, the Total number of the analysed points which refer to dist70 (of approximately 2000) and dist220 (of approximately 200) can be considered as independent on the camera's radial-movement angle change, while, dist110 shows a slight point-number decrease as this angle increases (from approximately 950 to approximately 600).

Charts 5 show the following.

Regarding all generated Cloud-points, the largest Point-cloud density is achieved in the case of dist70 (of approx. 0.9points $/ \mathrm{mm} 2$ ), then in the case of dist110 (of approx. 0.25 points $/ \mathrm{mm} 2$ ) and, finally, in the case of dist220 (of approx. 0.15 points $/ \mathrm{mm} 2$ ) (Chart 5(a)). The presented trend-lines show that, regardless of shooting distances, the achieved density is not dependent on the camera's radial-movement angle.

Similarly, the density of densimetrically both precise+accurate points that refer to dist70 is higher than that in the cases of dist110 and dist220 (Chart 5(b)). Also, the density of the analysed points which refer to dist70 (of approximately 0.27 points $/ \mathrm{mm} 2$ ) and dist 220 (of approximately 0.03 points $/ \mathrm{mm} 2$ ) may be treated as independent on the radial-camera's radialmovement angle change, while, dist110 shows a slight decrease in density as this angle increases (from approx. 0.12 points/mm2 to approx. 0.05 points $/ \mathrm{mm} 2$ ). 


\section{CONCLUSIONS AND OUTLOOK}

The influence of the investigated determinants ([object-to-camera distances] and [camera's radial-movement angles/station-points numbers]) on the achieved Point-cloud Density-quality is described indirectly - based on the usage of calculated percentage values of the "Object's Photo-Coverage" / "OPC" (directly taken over from the referral experiment [2]) (Table 2).

Bearing in mind the facts underlined in the previous Chapter, it is possible to draw the following conclusions:

1. Regardless of the values of the Object's Photo-Coverage, the Abundance percentage of densimetrically both precise+accurate points is not prone to the camera's radialmovement angle change. The highest (and almost identical) Abundance percentage of these points (of approx 60\%) refers to the cases of OPC- $0.7 \%$ and OPC-1.3\%, while the case of OPC- $2.1 \%$ is characterized by a lower Abundance percentage (of approx. $30 \%$ in average) (Chart 1(a)).

Table 2 Calculated values of "(Surface) Resolution" and "Object's Photo-Coverage" as a function of three chosen object-to-camera distances and a 10mm stick's diameter (Source: Djordjevic et al. [2])

\begin{tabular}{lccc}
\hline Calculated Parameters/ & Dist70cm & Dist110cm & Dist220cm \\
Distances & & & \\
\hline Object (Surface) Resolution & $0.1992313545 /$ & $0.3130778428 /$ & $0.66261556856 /$ \\
(in mm/pxl) & 0.1991452699 & 0.312942567 & 0.625885134 \\
\hline Object's Photo-Coverage & & & \\
(“OPC”) & approx. 2.1 & approx. 1.3 & approx. 0.7 \\
(in percentage of Sensor/ & & & \\
Image Width) & & & \\
\hline
\end{tabular}

2. In the cases of OPC- $0.7 \%$ and OPC- $1.3 \%$, the difference between the Abundance percentages of densimetrically both precise+accurate points and their corresponding statistically acceptable Abundance percentage (of 50\% of all generated points) is in the form of surplus only (positive trend). In addition, the surplus - related to the case of OPC- $07 \%$ (of approx. 9\% in average) is independent on the camera's radial-movement angle change, while the surplus which refers to OPC-1.3\% shows a slight increasing tendency (from approx. 5\% to approx. 10\%) as the camera's radial-movement angle increases. Only OPC-2.1\% shows a deficit of densimetrically both precise+accurate generated points (negative trend) - with a tendency of a slight deficit increase as the camera's radial-movement angle increases (from approx. $18 \%$ to approx $22 \%$ ). Because of such a small changing rate, this behaviour can also be considered as independent on the camera's radial-movement angle (Chart 2(a)).

3. The smallest distance/densimetric error (i.e. the largest closeness between neighbouring Cloud-points themselves) refers to densimetrically both precise+accurate points. In the case of OPC-2.1\%, the densimetric error (of approximately 0.35) can be considered as independent on the camera's radial-movement angle, while the two other cases show an obvious angledependency. Namely, in the case of OPC-1.3\%, there is a slight densimetric error decrease (from approximately 0.25 to approximately 0.20 ) as the camera's radial-movement angle increases, while the characteristic of the case of OPC- $0.7 \%$ is a slight densimetric error increase 
(from approximately 0.18 to approximately 0.21 ) as the camera's radial-movement angle increases (Chart 3(a)).

4. Because the experimental Point-clouds - related to the cases of OPC- $0.7 \%$ and OPC- $1.3 \%$ consist of a majority of densimetrically both precise+accurate points (with regard to all created points / Charts 1 and 4), their global/resulting Density-quality dominantly affects this type of points. It means that the Density-quality of the foregoing Point-clouds is characterized by both the densimetric precision and the densimetric accuracy, regardless of their achieved density level (Chart 5(b)). On the other side, the Point-cloud that refers to the case of OPC-2.1\% is more precise but less accurate in the densimetric sense (due to a drastically smaller number of those points with respect to the others / Charts 1 and 4).

The highest density level (based on the presence of densimetrically both precise+ accurate points) refers to the case of OPC- $2.1 \%$ (approximately 0.27 points $/ \mathrm{mm} 2$ ), while the density of approximately 0.85 points $/ \mathrm{mm} 2$ (in average) refers to the case of OPC- $1.3 \%$. The density level of OPC- $0.7 \%$ (of approximately 0.03 points $/ \mathrm{mm} 2$ ) is too small and cannot actually be declared as a density-indicator but as a "sparsity qualifier".

Generally, according to an artificial (purified) experimental scene used, the conclusion is that with the chosen focal lengths/object-to-camera distances, with shooting directions perpendicular to the axis of that object, with station-points uniformly radially distributed around it (at a circle of 360deg), and with the obtained values of photogrammetric-software process-quality outputs which belong to the recommended ranges, the achieved density-level of the created Point-clouds may be treated as independent on the camera's radial-movement angle but dependent on the percentage of the „Object's Photo-Coverage”: the lower the Coverage, the lower the density. Also, regardless of the Coverage level, the majority of the generated points are generally more "densimetrically" precise than they are "densimetrically" accurate.

Finally, as mentioned earlier, one must bear in mind that in the case of ,smaller" shooting distances (i.e. of higher OPC's values), an insufficient number of "natural" and "RAD" targets causes an unavoidable densimetric-quality decrease (affected by a quality decline of the outcomes of the point-marking and point-referencing procedures: the smaller the presence of points whose patterns can be recognized as photogrammetric targets, the less successful the marking and referencing procedure [1], [4]). So, it is recommended to obtain an adequate number of such targets in more "depth-planes" - especially in those located in the object's closer surrounding. But, the term "adequate" ought to be understood relatively, because this number is a matter of the selected photogrammetric software requirements as well as of a concrete architectural/urban configuration and selected movement-path geometry.

Except for the already investigated the metric- and density qualifiers (and their common role in a global quality valorization of photogrammetrically created Point-clouds as digital representations of the existent linear architectural/urban objects/elements), there are other important qualifiers that ought to be explored in the future: roughness and curvature. 


\section{REFERENCES}

1. G. Deng, "Practical testing and evaluating of the EOS Photomodeler, an off-the-shelf digital close-range photogrammetric software package", Department of Geodesy and Geomatics Engineering: University of New Brunswick, Fredericton, N.B., Canada, 1999.

2. Dj. Djordjevic, G. Djukanovic and D. Filipovic, "Quantifying the Metric-quality of linear object's pointclouds as a function of shooting distances and number of camera positions i.e. shooting directions", 4th International Scientific Conference on Geometry and Graphics - Mongeometrija 2014, Vlasina, Serbia, pp. 207-226, 2014.

3. Dj. Djordjevic, G. Djukanovic and D. Filipovic, "Linear object's point-clouds obtained for horizontal shooting directions: quantifying its metric and density quality as a function of object's inclination angle", Journal of Industrial Design and Engineering Graphics, vol. 10: Section 2, (Special Issue ICEGD 2015), pp. 5-14, 2015.

4. Eos Systems Inc., PhotoModeler Scanner User's Manual, 2012 (http://www.photomodeler.com) [Accessed: 17th July 2012].

5. Eos Systems Inc., "Quantifying the accuracy of dense surface modelling within PhotoModeler Scanner", (http://photomodeler.com/applications/documents/DSMAccuracy2012.pdf) [Accessed: 31st May 2013].

6. D. Girardeau-Montaut, CloudCompare v.2.1. Tutorial, (http://www.danielgm.net/cc) [Accessed: 22nd April 2014].

7. W. Karel and K. Kraus, "Quality Parameters of Digital Terrain Models", Institute of Photogrammetry and Remote Sensing (I.P.F.): Vienna University of Technology, Austria, 2006, (http://www.ipf.tuwien.ac.at/ publications/2006/Karel_Kraus_QualityPar4DTM.pdf) [Accessed: 22nd April 2014].

8. J.T.C. Lopez, Fotogrametria practica. Punto Arquitectura S.L.P., Ediciones Tantin, Torrelavega/ Cantabria, Espana, 2012.

9. A. Neffra and A. Bureau, Aerial and Close-Range Photogrammetric Technology: Providing Resource Documentation, Interpretation, and Preservation. Department of Land Management, National Operations Center, (Technical Note No. 428, Denver, Colorado 80225, USA, 2008).

\section{KVANTIFIKOVANJE KVALITETA GUSTINE FOTOGRAMETRIJSKI GENERISANIH OBLAKA TAČAKA LINIJSKIH ARHITEKTONSKO-URBANISTICKIH ELEMENATA U FUNKCIJI DISTANCE SA KOJE SE VRSI SNIMANJE I BROJA POZICIJA FOTOAPARATA TJ. PRAVACA SNIMANJA}

Rad istražuje uticaj distance snimanja i broja korišćenih pozicija fotoaparata tj. pravaca snimanja na postignuti kvalitet gustine fotogrametrijski generisanih oblaka tačaka kao digitalnih reprezentacija postojećih linijskih arhitektonsko-urbanističkih objekata/elemenata.

Zaključeno je da za koriščeno apstraktno (pojednostavljeno) eksperimentalno okruženje, za izabrane žižne daljine/distance sa kojih se fotografiše fokusirani objekat, pravce snimanja upravne na njegovu osu,za pozicije fotoaparata ravnomerno radijalno rasporedjene oko te ose (u punom krugu), kao i za dobijene vrednosti izlaznih papametara kvaliteta relizovanog fotogrametrisjkog procesinga (processquality output values) koje su u preporučenom opsegu, osvareni nivo gustine generisanih oblaka tačaka ne zavisi od uglovnog koraka rotacije fotoaparata, već od procenta zastupljenosti objekta na fotografiji (,Object's Photo-Coverage“): ukoliko je ovaj procenat "zastupljenosti" manji i gustina je manja. Takodje, nezavisno od nivoa upravo te "zastupljenosti, generisane tačke (sa aspekta gustine), generalno više karakteriše ostvarena preciznost ("densimetric precision") nego tačnost ("densimetric accuracy").

Ključne reči: arhitektonska fotogrametrija, 3D foto-modeling, oblak tačaka, gustina, preciznost, tačnost 